\section{The Good Doctor}

\section{Damon Galgut}

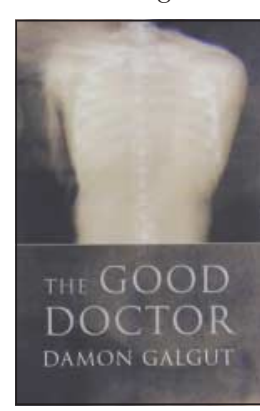

S hortlisted for this year's Man Booker prize, The Good Doctor is a tale of personal conscience and its outcomes. The novel tells the story of two doctors and the rural hospital in which they work. The hospital is dilapidated and ghostly, with few patients passing through its doors, and is blighted by lack of funds and the indifference of its staff. Its location is bleak: the failed and forgotten capital of a South African homeland, one of the arid and fruitless areas in which the black nations were made to live during the apartheid years.

The novel's narrator, Frank Eloff, is a self centred and underachieving doctor whose lack of motivation in his work has left him trapped in a junior position. $\mathrm{He}$ is tormented by the memory of his broken marriage and his part in carrying out acts of torture during his army service, and he feels that his career is forever being compared with that of his celebrity doctor father. His oblivion is disturbed, however, when he is forced to share his room with a new doctor, Laurence Waters.

Laurence is young, recently qualified, and filled with wide eyed idealism. Although a rural internship is compulsory under a new government scheme, Laurence chooses to be posted to this difficult area. He sees it as a way to effect real change, and, coming from humble beginnings, he strives to help the poor surrounding villages by setting up travelling clinics. However, when Laurence's girlfriend, Zanele (another idealist desperate to save the world), arrives, the motives for Laurence's good intentions are called into question.

The Good Doctor may be set in South Africa, but it addresses issues common to medicine everywhere-the notion of personal gain and the motivation behind morality. Can the desire to help the world be truly altruistic?

The only failing of this novel is that the hospital's immediate past, before Laurence's arrival, is somewhat unrealistic. It seems slightly unbelievable that no one before Laurence had attempted to change things or indeed been anything other than indifferent towards the hospital's shortcomings.

Despite this, author Damon Galgut has created something fresh and strong in this novel. It is a superb read, with a powerful sense of dark intrigue.

\section{Andrew Iles BMJ Clegg scholar}

ailes@bmj.com

\section{A Short History of Nearly Everything Bill Bryson}

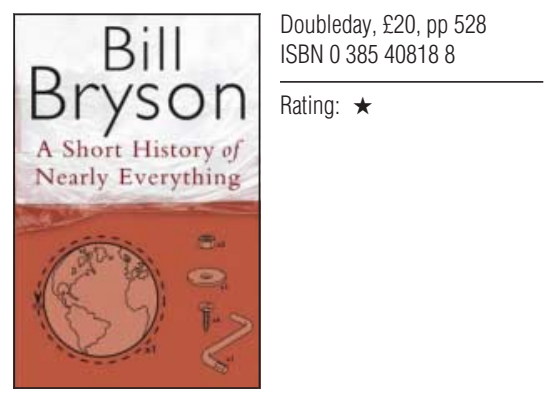

$\mathrm{I}$ n 1993, when there was a Tory government in the United Kingdom, the then minister for science, William Waldegrave, issued a challenge to physicists who were lobbying him for money to pay for their colossally expensive experiments. Could they answer, on a single page of A4, the questions: "What is the Higgs boson, and why do we want to find it?" As it happened, they could, as you can see by going to http://hepwww.ph.qmw.ac.uk/epp/higgs. html. But the incident prompts questions about the way the United Kingdom decides priorities in funding its research. Might it

Items reviewed are rated on a 4 star scale (4=excellent) not be better to have a minister who knew something about his portfolio? And it reminds us that even highly educated and intelligent people-Waldegrave is a fellow of All Souls, Oxford-feel no shame about their ignorance of scientific matters. Imagine the derision if he had asked a bunch of literary academics for a one page answer to "Who was T S Eliot and why is The Waste Land an important poem?"

Bill Bryson, bestselling author of travel books, didn't learn much science at school either. He was comfortable with his belief that science was supremely dull. That is until one day, gazing down at the moon-lit Pacific on a long haul flight, an epiphany occurred. How was it, he asked himself, that he could be so uninterested in the workings of the planet that he inhabited? He set out to remedy the deficiency, partly by reading but also by visiting scientists and getting them to explain what they were doing and why they were doing it. He spent three years on his quest-about the same time as an undergraduate course in a scientific subject-and now reckons that he knows enough volcanology, evolutionary biology, and particle physics to explain these things to the rest of us.

The strength of the book is its racy and easy to read style. Bryson is good both on the scientists he has met and the historical figures that he has encountered in his reading. You will enjoy, for example, his description of the Reverend Robert Evans, whose savant skills of spatial memory give him spectacular success in his nightly search for supernovae, or of J B S Haldane who, while researching submarine escape apparatus, showed not the slightest scruple in putting his colleagues and family in harm's way in a decompression chamber.

The trouble is that this is just about the book's only strength. This 500 page volume isn't an exposition of science. It's a bumper book of jaw-dropping facts transformed into a jaunty narrative by a professional writer. There is almost no attempt to explain anything that could be called a scientific principle or to show what follows from it. Newton's universal law of gravitation gets a paragraph; thermodynamics is covered in a footnote. And a number of errors make one wonder whether its author always grasped what he was told. Peter Medawar once epitomised a virus as "a piece of bad news wrapped in protein." Bryson calls it a memorable phrase but by misquoting it as "a piece of nucleic acid surrounded by bad news" robs it of both sense and wit.

There is a famous story, recounted in the book, of how the New York Times, wanting to run a piece on relativity, unaccountably chose its golfing correspondent, Henry Crouch, to interview Einstein. A sensitive man might have detected an uncomfortable parallel. Bryson is cool enough to remark that Crouch was hopelessly out of his depth.

Christopher Martyn associate editor, BMJ cmartyn@bmj.com, 


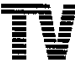

\section{The Human Mind}

BBC 1,1 to 15 October at 9 pm

\section{Rating: $\star \star \star$} obert Winston has developed his dreams of previous media doctors. First appearing in powerful human interest documentaries, rooted in his specialty of obstetrics, he has now transmuted into a TV icon. Introducing this, his latest three part series, Winston said he was going to take us to where no TV doc had been before, to "the final frontier" of medical science, "the human mind." But hold on a minute, what's an obstetrician doing talking about the brain? Has Winston strayed too far from his home turf? Would this series be his final frontier?

Until recently, television tackled medical science in a pretty formal way. In the $1970 \mathrm{~s}$, in The Body in Question, Jonathan Miller worthily analysed the history of medicine with a renaissance intensity. Since then, we have had numerous episodic medical documentaries of the talking-head-boffin variety (for example, in the BBC's long-running Horizon series).

In the past few years however, television has become more daring and less deferen-
$\mathrm{R}$ television career beyond the wildest

tial towards our stock-in-trade. It is no longer enough to show what doctors have to say about patients and their conditions. Now, it is de rigueur to be entertained by the doctor, the patient, and the condition itself. So, with the latter, the wizardry of special effects allows us to whoosh down gullets and cascade through neural networks.

There seems to be almost no limit to how far people are prepared to go to get on television, even if it means being accompanied by cameras into the privacy of a consulting room. And in Robert Winston, the small screen has discovered an entertainer with gravitas. And a moustache. Adding a measure of serious authority (Saddam is reputed to have learnt this notion from Stalin), the hefty black moustache is also, unashamedly, part of Winston's performance. We see-and surely here the incongruity is deliberate-a professor who is also a peer who is quite happy to do his own stunts and even look ridiculous, as long as it delivers an informative, scientific message Perhaps it is no coincidence that Robert Winston is an obstetrician. In this age of play-it-safe ratings paranoia, canny BBC programmers have discovered a professional whom they know their audience will trust. Lord Winston delivers (literally).

There is no denying the slick production of this latest series. We started with a heart-thumping representation of a synaptic cleft-a stunning gorge in an exotic, highland location-that our hero bravely straddled by means of a rope. The rope's

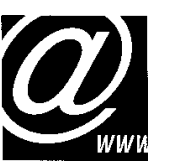

Lesbian health An editorial in this week's $B M J$ appeals for greater recognition of the special needs of women who have sex with women ( $p$ 939). Online health information for lesbians is burgeoning, but often it is to be found within broader gay health sites.

However, there are sites specific to women who have sex with women. WEBSITE www.lesbianhealth.org.uk highlights sexual and mental health risks and the OF THE topics of breast cancer, diet, smoking, and exercise. http://lesbianhealthinfo.org WEEK claims to be "a virtual potluck" of information about lesbian health, but mostly describes the work of the University of California Lesbian Research Center. Commercial endeavour masquerades as health information at Lesbian Health Net, which markets natural nutritional products specially formulated to meet the unique needs of lesbians (http://lesbianhealth.net/).

The relevant sections of the American (www.4woman.gov/faq/Lesbian.htm) and Canadian (www.hc-sc.gc.ca/english/women/facts issues/lesbian health. $\mathrm{htm}$ ) government women's health pages offer some guidance about the frequency with which lesbian women should have pap smears, screening for sexually transmitted infections, and mammograms. And an excellent review available full text at the Medical Journal of Australia emphasises the role of discrimination in creating health inequalities for lesbian women (www.mja.com.au/public/issues/178_12_160603/mcn10852_fm.html).

The outstanding health resource at McMaster University in Ontario, Canada, includes an extensive list of links (http://hsl.mcmaster.ca/tomflem/gay.html).

The pharmaceutical company funded website of the influential US Gay and Lesbian Medical Association is a comprehensive resource for both providers and patients (www.glma.org). Emphasising the association's advocacy work to end homophobia in health care, the site is a wide ranging and extremely well organised collection of news, research, working papers, and clinical information.

Jocalyn Clark

editorial

registrar

jclark@ It includes an online searchable database to help find a gay friendly doctor (in north America) and recommendations for the "top ten" things lesbians should ask their doctors. The website of its UK contemporary, the Gay and Lesbian

bmj.com

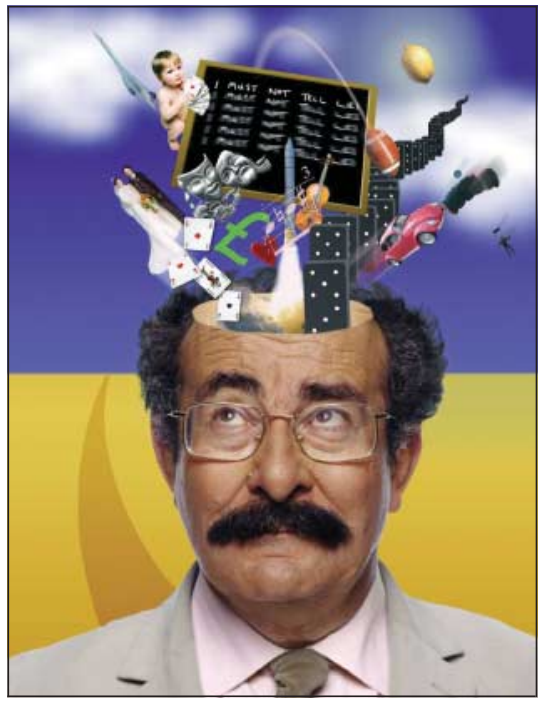

Has Lord Winston strayed too far from his home turf?

consequent development into a prefabricated bridge deftly illustrated the principle of neuronal facilitation, which shifted neatly into the real life story of a 43 year old housewife who wanted to become a midwife. Robert spelt it out, to her and us, that if she wanted to achieve this, she was going to have to "physically restructure her brain."

Subsequent development of this theme, in the first programme, covered possible avenues for the amelioration of such processes (omega 3 fish oil trials in sluggish school kids). We then learnt how the brain programmed (and rewired) its motor cortex even by the visualisation of complex movements and how we could train our memories to absorb capacious lists of trivia. Finally, Winston the neuroscientist started to transform (before our very eyes) into Winston the neuro-psychoanalyst, by explaining possible cognitive processes that might underlie subconscious memory.

The two subsequent programmes were equally entertaining and informative, covering such issues as the development of personality and how dysfunctional elements of personality could be altered in adults by psychological intervention. I was also instructed how to read faces and how to lie more convincingly. There was even psychohistorical analysis of a certain meeting in 1938, explaining how Hitler's superior mind reading (and lying) skills led to devastating international conflict

Not bad for 60 minutes of prime time, especially when you look at the competition. This month, for example, the same channel is going to be treating us to the delights of Celebrity Dog School. I don't think Robert will be on it, but, in The Human Mind he was shown pondering by a pond, having a brainwave, and then walking off with his dalmatian, all to demonstrate the cognitive benefits of relaxation. Maybe this isn't his final frontier-maybe it's only the beginning.

Iain McClure consultant child and adolescent psychiatrist, Vale of Leven Hospital, Alexandria imcclure@vol.scot.nhs.uk 


\section{NETLINES}

- Rheumatology problems abound in clinical practice and sometimes it is helpful to go back to basics and learn the fundamentals of the specialty. JointZone (www.jointzone.org.uk), supported by the UK based Arthritis Research Campaign, is a user friendly and clearly written resource that would be ideal for any doctor who wants to brush up his or her knowledge, as well as for medical students and nursing staff. With case studies, a review of common problems, and sections on investigations and management and information about physical examination, this site offers much to many.

- The British Heart Foundation has produced an amazing collection of statistics on cardiovascular disease (www. heartstats.org/). There is a huge volume of data here-probably the easiest way to obtain an overview is to go to the A-Z index and scroll down. Within each subject area, documents can be downloaded in commonly used file formats.

- For neat, concise information on eye diseases check out the Handbook of Ocular Disease Management (www.revoptom.com/HANDBOOK/ default.htm). Although this is part of the site of a United States based optometry journal, it is also suitable for primary care and junior hospital staff. The front page provides links to seven main subject areas, such as eyelids and eyelashes and oculosystemic disease, each of which contain a bundle of articles. The whole collection covers many common eye scenarios and is searchable by keyword.

- Dermatology sites that contain colour pictures and a short accompanying description are popular with their target audience. http://medicine.ucsd.edu/ clinicalimg/Skin.html is a good example. The site is a catalogue of clinical skin images from the University of California, comprising a simple alphabetical hypertext list. Just clicking on any of the conditions brings up an image. Although this is a relatively small collection, there is enough material here for a quick revision course on common and not so common dermatological conditions.

- The internet is now an established port of call for anyone looking for information about rare medical diseases. Those whose interest is bone tumours may want to check out a site that claims to be the web's most comprehensive source for bone tumour information (http://

bonetumor.org/). An alphabetical list of bone tumours can be found by clicking the tumour information tab at the top of the page. There is also a learning resources section.

Harry Brown general practitioner, Leeds DrHarry@DrHarry.co.uk

We welcome suggestions for websites to be included in future Netlines. Readers should contact Harry Brown at the above email address.

\section{PERSONAL VIEWS}

\section{Lessons we can learn from organ retention}

I

n 2001 and 2002 I was involved with the Birmingham Children's Hospital's organ retention inquiry. Most of the parents who contacted the hospital were interviewed not by managers or nurses but by clinicians. Half of these clinicians were paediatric anaesthetists who had had no involvement with these families before the inquiry and could provide impartial support, as well as broad knowledge of anatomy, physiology, and surgical techniques when explaining causes of illnesses and death.

I met 40 families, and it was a sobering experience to hear common themes of inadequacy of treatment. They showed a lot of anger, but very little was directed at me. Instead, many parents expressed appreciation for the discussion and explanations. I was privileged to be party to their individual emotions, expressions of love for their children, and dignity in their grief.

Most of the deaths had occurred many years previously, when information about the causes of illness and death was often lacking. Parents of children who died after cardiac surgery felt they had not had adequate explanations of the risks, leaving them with long term guilt about their responsibility for consenting to surgery. Many parents had had long term illness and depression since the death of their child. Management of critically ill children has changed radically since then, and hospital practices have altered tooparents are now encouraged to stay with their child at all times, unrestricted by visiting hours. Families spend as much time as necessary with the child after death, and there is greater input from counselling services. Parents remembered inconsistent communication and a lack of sympathy, but equally they remembered good, tender care and clear, compassionate explanations.

Consent for post mortem examination has now been radically updated, but traditionally it was taken by junior doctors who generally did not appreciate how long fixing for histology can take. The number of inquiries from parents about organ retention shows how few parents were adequately prepared and able to give informed consent. Several parents could not even remember a consent form, some felt they had been coerced into signing, and others found it difficult that a post mortem examination looked at all tissues, even sexual organs, when their child had had illnesses of the heart or brain. Some families found the retention of normal tissue for education distasteful. Many would not have given consent if they had had full knowledge of what a post mortem examination entailed.

As doctors we have tended towards paternalism. Information to parents was restricted to avoid further "unnecessary" distress. Early release for burial, before histology was complete and organs could be returned to the body, could be explained as an attempt to facilitate the family's grief. Now that their trust in the medical profession has been damaged by such revelations as retention of hearts and brains, parents find it difficult to see our actions as being in their best interests, particularly when they are at the height of their anger.

One of the main difficulties in dealing with the parents during the inquiry was the limited documentation available. After making contact with the hospital parents were offered access to their child's medical records. Several had questions about the recording of information that they remembered as inaccurate. In the earlier cases parents were given false implicit reassurances that because the organs were no longer held by the hospital they had never been removed and retained. Subsequent data collection from different sources showed further information. Once data were collected and had been approved by the Retained Organs Commission detailed information about each post mortem examination was available for parents. It was difficult to assess how much of each organ had been retained or how and when the remaining tissue had been disposed of once histology was complete. Attempts to describe incineration of clinical waste as "respectful disposal" were not always helpful. It was hard to get a balance between a frank and honest revelation of all information available and compassionate and supportive counselling of parents in deep distress. We came under some criticism for providing families with unsolicited and upsetting information.

Many families expressed their genuine desire to contribute to medical education "if only we'd been asked" and hoped to find some benefit in the removal of their child's organs. Unfortunately there was no information on how often slides or organs were looked at for the purposes of training or diagnosis. Most parents who took part in the inquiry did want return of organs for reburial, although those parents who did not feel strongly about this might not have contacted the hospital at all.

The issue of organ retention has often been hard for doctors to handle well. It has exposed our previous limitations but is valuable in helping us improve our relationship with patients and parents at all stages of their care.

Gillian Derrick consultant anaesthetist, Birmingham Children's Hospital, Birmingham gillian.derrick@bch.nhs.uk 


\section{Should elderly patients be made to sit in chairs?}

$\Lambda^{\circ}$ s a geriatrician I have encountered innumerable distressed elderly women in hospitals and nursing homes slumped and sliding out of chairs and begging to be allowed to lie down. What is the evidence that elderly patients benefit from extended periods of sitting in chairs? How many patients need further investigation or palliative care rather than "mobilisation"? What about patients' rights to reject such "treatment"?

Surgeons introduced early "ambulation" after operations in the $1940 \mathrm{~s}$ as an alternative to the time honoured tradition of nursing virtually all patients in bed. As curative surgery and other treatments became available, it was realised that prolonged inactivity not only did not help but might even retard recovery. An army of physiotherapists was recruited to help patients walk and become independent after treatment.

The most famous advocate of ambulation for elderly patients was Richard Asher, a humane iconoclast who liked to poke fun at the establishment. In a memorable paper, "The dangers of going to bed" (British Medical Journal 1947;ii:967-8), he wrote: "Look at the patient lying in bed. What a pathetic picture he makes! The blood clotting in his veins, the lime draining from his bones, the scybala stacking up his colon, the flesh rotting from his seat, the urine leaking from his distended bladder and the spirit evaporating from his soul." However, few if any proponents of ambulation seem to have read Asher's next paragraph: "I have painted a gloomy and unfair picture: it is not as bad as all that. There is much comfort and healing in the bed, and rest is essential for the management of many illnesses. My object has been to disclose the evils of overdose."

Today Asher would be concerned about an overdose of nursing in chairs. He would also appreciate the difference between his patients and elderly patients today. The average age in his wards was around 73 years. Most patients were quite fit but unable to be discharged because they had nowhere else to go. They responded well to being got up and given physiotherapy and occupational therapy. Today's elderly hospital patients are generally 10 years older, have several illnesses, and are either newly injured or very sick. Their short admission is usually confined to the period when they are acutely ill.

One problem of evidence based medicine is that research in healthy young volunteers may not apply to sick or elderly patients. In one frequently quoted study of the adverse effects of bed rest, healthy young men were immobilised in plaster casts for six to eight weeks. The main findings were a negative nitrogen balance, calcium loss, diminished muscle strength, and orthostatic intolerance. However, similar adverse effects have been shown when young men are seated immobile in chairs, and few studies have looked at the effects of bed rest in old people.

Lying down increases blood flow in leg veins and in the liver, lungs, and brain. Improved renal perfusion increases insulin clearance. Vasodilatation increases blood flow to internal organs, muscles, and skin. Conversely, standing or sitting causes reflex vasoconstriction. Patients who try to sleep in chairs complain of cold feet. Excretion of water and electrolytes is reduced in the upright position, especially in old people, causing leg oedema and fluid overload during the day and nocturia and incontinence at night. Prolonged sitting on long flights is known to cause venous thrombosis. Blood flow velocity in the common femoral vein is 20 times less in the sitting than in the supine position.

The importance of the recumbent position for relaxation and sleep is scarcely mentioned in textbooks. Besides the obvious effects on performance and memory, lack of sleep raises serum cortisol and catecholamine concentrations, reduces thyroid stimulating hormone, and increases lipid intolerance and the likelihood of diabetes. Production of anabolic hormones is increased during sleep, allowing tissue renewal and healing. Crossover trials showed that elderly orthopaedic patients who had shorter rather than longer sessions of chair nursing had a lower incidence of pressure sores, fatigue, tachycardia, hypotension, leg oedema, and constipation. They were also more independently mobile and were able to be discharged sooner.

A 1999 review of trials that compared prescribed bed rest with ambulation concluded that in all cases activity was better than bed rest. However, prescribed bed rest is not the same as rest resulting from felt need. Exercising little and often and sitting out of bed for meals where practicable are obviously important, but so is the need for rest after exertion and after meals. Mobile patients can choose whether to sit or lie down. Less mobile and sick patients should be sat out of bed, if at all, for periods of not more than one to two hours.

Mary Bliss consultant emeritus in geriatric medicine, Sevenoaks, Kent mary.bliss@virgin.net
SOUNDINGS

Judges

I had never had any particular desire to be a high court judge until Mr Justice Lightman, giving judgment on radio and television presenter Chris Evans' case against Virgin, called him a petulant, manipulative, lying prima donna. I have to say that an opportunity like that can make a whole life worthwhile. It is similar to the time at school when I punched Andrew Jenkins on the nose (shortly before being beaten to a pulp myself). Life affirming. But even with these potent attractions I don't think I would be quite comfortable being a judge (a somewhat hypothetical event). The difficulty is the necessary arbitrariness of having to impose order on a disordered world - to create categories when there are only gradations. It is like being faced interminably with those multiple choice questions in exams where you want to say "sometimes," but the only available answers are "yes" or "no."

I suspect that judges, like doctors, fall into two camps. Some make up their mind about a judgment (or a case) and build an argument showing the inevitability of their decision. The more honest delineate the grey areas and explain why they have, of necessity, made the best guess they can.

I started doing a law degree a couple of years ago with an open mind and a conviction that judges were right wing, bigoted old buffers. But, as always, the strength of my certainty seems inversely proportional to my knowledge of a subject. Many of the judgments I have to read dent my prejudices. Somewhat surprisingly, they usually seem to come from rather fair minded and clear thinking people.

It is certainly true that judges are not exactly representative of the world at large. They originate almost exclusively from a small cadre of public schools and Oxbridge. But I suppose Plato wouldn't have objected. And if the Daily Mail is as representative as its circulation suggests then maybe it is more important that judges are disinterested rather than representative.

In the end, though, the attraction of being a judge is not merely the possibility of being analytically rude. As doctors we spend our lives trying to keep everyone happy. We endlessly try to square the circle. It must be a kind of relief to know that, as a judge, whatever decision you make, you're going to piss off $50 \%$ of people. There's a certain elegant symmetry about that.

Kevin Barraclough general practitioner, Painswick, Gloucestershire 